\title{
Disease activity in acromegaly may be assessed 6 weeks after discontinuation of pegvisomant
}

\author{
W M Drake, R A Loureiro, C Parkinson ${ }^{1}$, J P Monson, G M Besser and P J Trainer ${ }^{2}$ \\ Department of Endocrinology, St Bartholomew's Hospital, London EC1A 7BE, UK, ${ }^{1}$ Department of Endocrinology, Ipswich Hospital, Ipswich IP4 5PD, \\ UK and ${ }^{2}$ Department of Endocrinology, Christie Hospital, Manchester M2O 4BX, UK
}

(Correspondence should be addressed toW M Drake; Email: w.m.drake@qmul.ac.uk)

\begin{abstract}
Objective: Pegvisomant, a modified growth hormone $(\mathrm{GH})$ molecule, is a novel medical therapy for acromegaly that functions as a GH receptor antagonist. Serum GH cannot be used as a marker of disease activity in patients taking this form of therapy, partly because GH levels rise on pegvisomant and partly because the drug cross-reacts with many routine $\mathrm{GH}$ assays. The purpose of this study was to assess the time for which it is necessary to discontinue pegvisomant prior to biochemical reassessment of acromegaly.

Design and methods: This was a retrospective study of 13 patients (seven male, median age 61 years, range 43-77) enrolled in two separate, open-label studies of the efficacy and tolerability of pegvisomant in the treatment of acromegaly. All had been taking a stable dose of pegvisomant (median dose $15 \mathrm{mg}$ daily, range 10-30) as monotherapy for at least 3 months before discontinuing the drug. After discontinuation of pegvisomant, serum IGF-I was measured at $0,2,4,6$ and 8 weeks in all patients. Serum GH (single sample) was measured in nine patients at 2, 4, 6 and 8 weeks, but not at baseline on account of the cross-reactivity of pegvisomant with the $\mathrm{GH}$ assay.

Results: Mean serum IGF-I rose from $210 \pm 105 \mathrm{ng} / \mathrm{ml}$ (S.D.) at baseline to $392 \pm 175 \mathrm{ng} / \mathrm{ml}$ at 2 weeks after discontinuation of pegvisomant $(P<0.0001)$. Although there was no statistically significant change in mean serum IGF-I beyond 2 weeks $(412 \pm 181,392 \pm 152$ and $399 \pm 150 \mathrm{ng} / \mathrm{ml}$ at 4,6 and 8 weeks respectively; $P=0.13$ ( 2 vs 4 weeks), 0.31 ( 4 vs 6 weeks) and 0.46 ( 6 vs 8 weeks), serum IGF-I rose by more than twice the interassay coefficient of variation (CV) in two of the 13 patients between weeks 2 and 4. The standard deviation of the difference in serum IGF-I between time points was calculated. The values declined from 118\% (weeks $0-2$ ) 17\%, 19.7\% and 10\% (weeks $2-4,4-6$ and 6-8 respectively). The expected measure if there was no systematic change in base would be $15 \%(1.4 \times$ interassay $\mathrm{CV})$. Mean serum GH was virtually unchanged at $2-8$ weeks after cessation of pegvisomant therapy.

Conclusions: These results suggest that the activity of acromegaly may be assessed by serum IGF-I levels 6 weeks after the discontinuation of pegvisomant.
\end{abstract}

European Journal of Endocrinology 152 47-51

\section{Introduction}

For patients with acromegaly treated with medical therapy, it is common clinical practice intermittently to discontinue treatment in order to assess underlying disease activity. This is particularly so for those awaiting the effects of pituitary irradiation, as the decline in the degree of growth hormone $(\mathrm{GH})$ hypersecretion over time may permit dose reductions (and, in some cases, discontinuation) of GH-lowering therapies such as dopamine agonists and somatostatin analogues. Although not systematically studied, most physicians experienced in the management of acromegaly accept that adequate washout times for medical therapies prior to biochemical reassessment include 5 weeks for bromocriptine and 2 weeks for short-acting subcutaneously injected octreotide (1); longer periods are required for longer-acting dopamine agonists such as cabergoline and slow-release formulations of somatostatin analogues. Pegvisomant is a genetically engineered GH analogue that has been developed for the treatment of acromegaly $(2,3)$. Unlike other medical therapies, pegvisomant makes no attempt to reduce $\mathrm{GH}$ secretion by the pituitary. Rather, the goal of therapy is inhibition of GH signal transduction with consequent reduction of insulin-like growth factor I (IGF-I) generation $(2,3)$. The fall in serum IGF-I concentrations in patients treated with pegvisomant is accompanied by a rise in serum GH concentrations, presumably, at least in part, consequent upon reduced feedback $(1,4)$. Further difficulties for disease monitoring arise on account of the structural homology between endogenous GH and pegvisomant, such that the drug cross-reacts with many $\mathrm{GH}$ assays in routine 
clinical use. Hence, serum GH concentrations cannot be used as a marker of disease activity in patients taking pegvisomant (5). The purpose of this study was to assess the time for which it is necessary to discontinue pegvisomant prior to biochemical reassessment of underlying disease activity in patients with acromegaly treated with this drug.

\section{Patients and methods}

\section{Patients}

Details of the 13 patients (seven male, median age 61, range 43-77) are given in Table 1 . All had active acromegaly and were enrolled in two separate, open-label studies of the efficacy and tolerability of pegvisomant in the treatment of acromegaly (6), for which they had provided ethical board-approved, informed consent. Pituitary hormone deficits were appropriately replaced (Table 1), with no change in doses during the course of the study.

\section{Study protocol}

The two separate open-label studies in which the patients were participating commenced in 1997 and 1998. In 1999, supplies of pegvisomant for clinical trial use became severely limited and many patients were forced to discontinue therapy. Most (10/13) of the patients reported here had received pituitary irradiation several years earlier, either as primary therapy or after non-curative surgery (Table 1). It was therefore considered clinically appropriate to reassess underlying disease activity in order to select an alternative medical therapy to pegvisomant. All had been taking a stable dose of pegvisomant (median dose $15 \mathrm{mg}$, range 10-30) (Table 1) as monotherapy for at least 3 months prior to discontinuing the drug.
After cessation of pegvisomant therapy, serum IGF-I and GH (single sample) were measured at 0800$1000 \mathrm{~h}$ after an overnight fast; at $0,2,4,6$ and 8 weeks (IGF-I, all patients); and at 2, 4, 6 and 8 weeks (GH, nine patients). No baseline $\mathrm{GH}$ sample was measured on account of the cross-reactivity of pegvisomant with routine clinical GH assays. After 8 weeks, all patients commenced standard doses of long-acting somatostatin analogues during conventional clinical follow-up.

\section{Assays}

Serum IGF-I was measured by an in-house RIA with acid-ethanol extraction (7), with inter- and intraassay coefficients of variation (CVs) of $10.4 \%$ and $2.7 \%$ respectively. Serum GH was quantitated by an immunoradiometric assay using Immulite 2000 (Diagnostic Products Corporation, Los Angeles, CA, USA), with inter- and intra-assay CVs of 5\%.

\section{Statistical analysis}

Serum GH and IGF-I concentrations at all time points were compared by Student's paired $t$-test, with statistical significance accepted at $P<0.05$. The standard deviations of the percentage changes were calculated in order to provide a measure of variability. If there was no underlying change in the individuals or any expected correlation in the errors associated with assay variability, this should equate to an unbiased estimate of $1.4(\sqrt{2}) \times$ the interassay $\mathrm{CV}$.

\section{Results}

Eleven of the 13 patients had serum IGF-I below the upper limit of the age-adjusted normal range at the start of the study (Fig. 1). Mean serum IGF-I rose from $210 \pm 109 \mathrm{ng} / \mathrm{ml}$ (S.D.) at baseline to $391 \pm 179 \mathrm{ng} / \mathrm{ml}$

Table 1 Clinical details of the 13 patients.

\begin{tabular}{|c|c|c|c|c|c|c|}
\hline Patient no. & Age & Gender & $\begin{array}{l}\text { Treated pituitary hormone } \\
\text { deficiencies }\end{array}$ & $\begin{array}{l}\text { Previous surgery } \\
\text { (year and route) }\end{array}$ & $\begin{array}{l}\text { Radiotherapy } \\
\text { dose (year) } \\
\text { (all EBRT) }\end{array}$ & $\begin{array}{l}\text { Pegvisomant } \\
\text { dose }(\mathrm{mg})\end{array}$ \\
\hline 1 & 74 & $\mathrm{~F}$ & None & None & None & 10 \\
\hline 2 & 55 & M & None & None & None & 15 \\
\hline 3 & 43 & M & $\mathrm{FSH} / \mathrm{LH}, \mathrm{ACTH}$ & 1988, 1990 (TSS) & 4500 cGy (1990) & 10 \\
\hline 4 & 63 & $\mathrm{~F}$ & None & 1997 (TSS) & 4500 cGy (1997) & 20 \\
\hline 5 & 63 & $\mathrm{~F}$ & None & 1995 (TSS) & 4500 cGy (1995) & 15 \\
\hline 6 & 67 & $\mathrm{~F}$ & $\mathrm{FSH} / \mathrm{LH}, \mathrm{ACTH}, \mathrm{TSH}$ & None & 4500 cGy (1989) & 15 \\
\hline 7 & 43 & M & $\mathrm{FSH} / \mathrm{LH}, \mathrm{ACTH}$ & 1981 (TFS) & 4000 cGy (1982) & 20 \\
\hline 8 & 44 & M & None & 1995, 1996 (TSS) & 4500 cGy (1995) & 10 \\
\hline 9 & 69 & M & None & None & None & 10 \\
\hline 10 & 55 & $\mathrm{~F}$ & ACTH, TSH & 1990 (TSS) & 4500 cGy (1990) & 15 \\
\hline 11 & 77 & M & FSH/LH, ACTH & None & 4500 cGy (1993) & 10 \\
\hline 12 & 47 & $\mathrm{~F}$ & FSH/LH, ACTH, TSH & 1988 (TSS) & 4500 cGy (1988) & 30 \\
\hline 13 & 61 & M & $\mathrm{TSH} / \mathrm{LH}$ & 1988 (TSS) & 4500 cGy (1991) & 30 \\
\hline
\end{tabular}

TSS = trans-sphenoidal surgery; TFS $=$ transfrontal surgery; EBRT = external beam radiotherapy; $\mathrm{FSH}=$ follicle-stimulating hormone; $\mathrm{LH}=$ luteinising hormone; $\mathrm{TSH}=$ thyroid-stimulating hormone; $\mathrm{ACTH}=$ adrenocorticotrophin. 


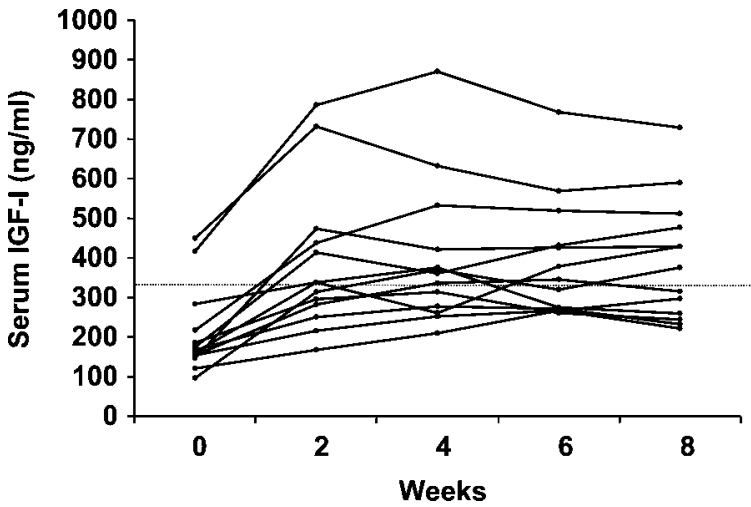

Figure 1 Serum IGF-I vs time in patients with acromegaly who discontinue pegvisomant therapy. The dotted line denotes the upper limit of the age-related reference range for the youngest patient in the study.

2 weeks after discontinuation of pegvisomant (Student's $t$-test; $P<0.0001)$ (Fig. 1). Although there was no statistically significant change thereafter $(412 \pm 181$, $392 \pm 152$ and $399 \pm 150 \mathrm{ng} / \mathrm{ml}$ at 4,6 and 8 weeks; $P=0.13,0.31$ and 0.46 respectively), serum IGF-I rose by twice the $\mathrm{CV}$ of the assay in $2 / 13$ patients $(27 \%)$. For each of these patients, this increment resulted in a value well within the age-adjusted normal range at week 2, but well into the acromegalic range thereafter. Furthermore, the variability in serum IGF-I between time points (as determined by the above formula) fell from $118 \%$ (weeks $0-2$ ) to $17 \%, 20 \%$ and $11 \%$ (weeks $2-4,4-6$ and $6-8$ respectively) (Fig. 1).

Of the total of 13 patients, GH data were available in nine; in these, the mean serum GH was unchanged at $2-8$ weeks $(6.9 \pm 5.6$ vs $6.2 \pm 3.1$ vs $6.9 \pm 3.9$ vs $7.9 \pm 4.5$ at $2,4,6$ and 8 weeks respectively; all $P>0.3$ ).

\section{Discussion}

Data from two large-scale, multicentre studies indicate that pegvisomant, the first $\mathrm{GH}$ receptor antagonist developed for clinical use, is the most effective medical therapy for acromegaly to date $(1,6)$. Over $97 \%$ of patients with acromegaly achieved normal serum IGFI concentration when treated with this drug, irrespective of the previous efficacy of other medical therapies (6). Experience to date suggests that pegvisomant may be a particularly suitable treatment for patients with acromegaly and coexistent diabetes mellitus (8), and for patients whose disease is partially or completely unresponsive to somatostatin analogue therapy (9). Given that these patients are frequently the most challenging to treat, it is probable that they will have received pituitary irradiation in order to help achieve satisfactory serum GH/IGF-I concentrations. This, in turn, means that these patients are likely to need to discontinue pegvisomant therapy at intervals in order to monitor underlying disease activity. The goal of this study was therefore to provide endocrine physicians with practical advice on the time for which it is necessary to discontinue pegvisomant prior to biochemical reassessment in acromegalic patients treated with this drug.

Accepting the limitations of circulating IGF-I to reflect whole-body exposure to $\mathrm{GH}$, the time for full disease activity to become biochemically apparent after cessation of pegvisomant depends on the rate of decline in drug concentrations and the time for a given $\mathrm{GH}$ stimulus to effect an IGF-I response. The half-life of pegvisomant in the circulation is at least $72 \mathrm{~h}$; hence, $2-3$ weeks after cessation of therapy ( five half-lives), drug concentrations are likely to be sufficiently low as to be associated with little or no inhibition of GH signal transduction. Few data exist on the timescale over which changes in serum IGF-I levels occur after an abrupt alteration in GH hypersecretion (as in surgical adenomectomy or commencement of short-acting subcutaneously injected octreotide). However, in the context of hypopituitarism treated with recombinant human (rh) GH, it is well established that serum IGF-I concentrations plateau within 2 weeks of an increment in GH dose (10). Taken together, these theoretical pharmacokinetic factors $(2-3$ weeks for pegvisomant to fall to low levels; maximum of 2 weeks for a change in IGFI levels after an increase in GH signalling) correlate reasonably well with the data presented here, in which serum IGF-I appears to plateau 4-6 weeks after cessation of pegvisomant therapy (Fig. 2).

In reality, the time course over which maximum disease activity emerges after cessation of pegvisomant is a complex integral of the above factors and likely to differ between patients. Measures of variability between time points provide an indicator of whether the emerging GH/IGF-I axis has reached equilibrium, but the standard deviation of paired differences between IGF-I concentrations is inadequate for this purpose, as it takes no account of any trend over time.

The standard deviation of the differences between adjacent time points for serum IGF-I fell from 118\%

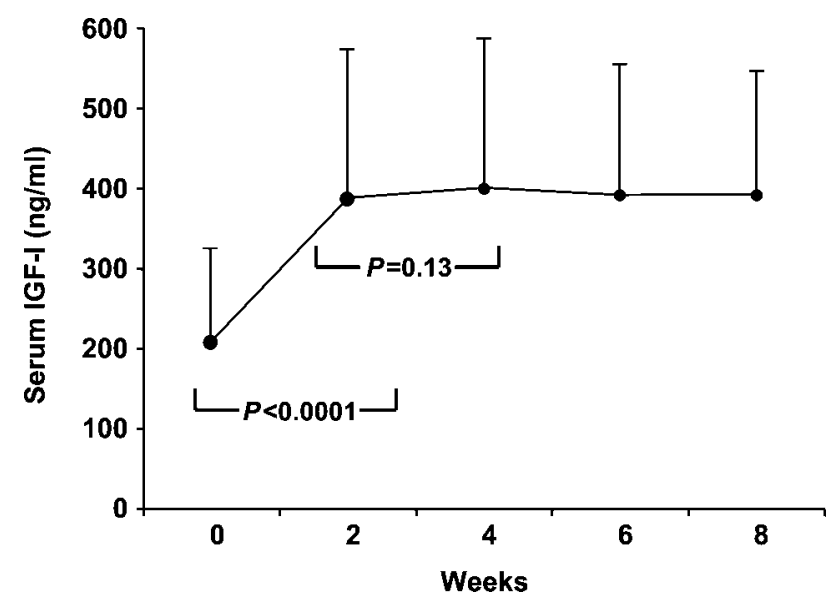

Figure 2 Mean serum IGF-I vs time in patients with acromegaly who discontinue pegvisomant therapy. 


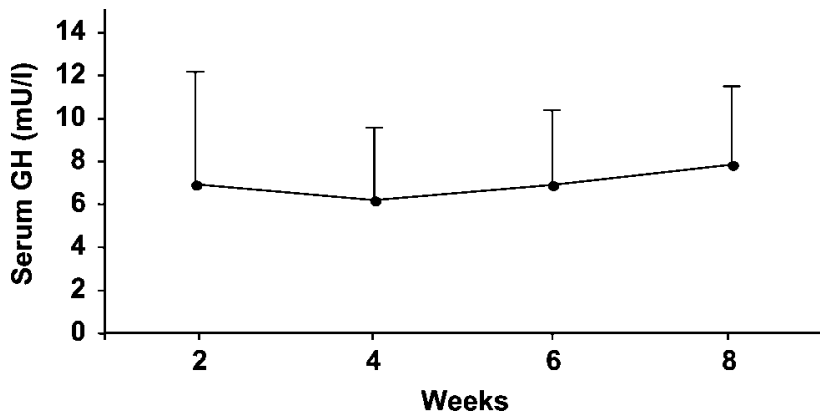

Figure 3 Serum GH vs time in patients with acromegaly who discontinue pegvisomant therapy (mean, S.D.).

at week 2 to $17 \%, 20 \%$ and $11 \%$ at weeks 4,6 and 8 respectively. Given an expected variability of $15 \%(1.4 \times$ interassay $\mathrm{CV}$ ), these data suggest that, although there was no statistically significant change in mean serum IGF-I after 2 weeks, not all patients exhibited maximum disease activity at this time. No single parameter alone dictates the decision to continue maintenance medical therapy in acromegaly, which is based on a combination of clinical evaluation and serum GH and IGF-I concentrations. Although the potential problems associated with relying solely on serum IGF-I concentrations for diagnosis and disease monitoring have been well documented (11), measurement of this GHdependent peptide is an important tool that contributes to clinical decision making. Taking account of the variability between patients in displaying maximum disease activity, it seems clinically appropriate to wait 6 weeks after cessation of pegvisomant therapy before biochemical re-evaluation.

The structural homology between pegvisomant and endogenous GH provides a further, theoretical reason to wait longer than the 2 weeks beyond which there was no statistically significant increment in serum IGF-I. The presence of polyethylene glycol residues on pegvisomant greatly reduces the affinity of the mutant peptide for the GH receptor, such that concentrations of drug 1000-fold in excess of endogenous GH are required for sufficient antagonism to control IGF-I generation. Hence, although there is likely to be little inhibition of GH signal transduction 2-3 weeks (five half-lives) after cessation of pegvisomant therapy, it is likely that sufficient concentrations of drug will still be present to interfere with many routine clinical assays. Although this does not appear to have been a major complicating factor in our GH assay (Fig. 3), it cannot be assumed that this will be the case in those used in all endocrine centres.

In summary, these data suggest that, in patients with acromegaly treated with pegvisomant, underlying disease activity may be reassessed 6 weeks after cessation of drug. No evidence exists, in this study, for continuing elevation of serum GH concentrations at this time, but further data, from different centres, are required to be confident that low serum concentrations of pegvisomant will not interfere with GH measurements in other routine clinical assays. We hope that these data will be of practical use to endocrine physicians as they start to gain experience with this important new medical therapy for acromegaly.

\section{Acknowledgements}

We thank Mrs Frances Fode and Mrs Margaret Roberts for technical assistance with the collection of samples, and Mrs Enid Hennessy for expert statistical advice. The Department of Endocrinology receives financial support from Pfizer Inc. for its research into growth and growth factors.

\section{References}

1 Trainer PJ, Drake WM, Katznelson L, Freda PU, Herman-Bonert V, van der Lely AJ, Dimaraki EV, Stewart PM, Friend KE, Vance ML, Besser GM, Scarlett JA, Thorner MO, Parkinson C, Klibanski A, Powell JS, Barkan AL, Sheppard MC, Malsonado M, Rose DR, Clemmons DR, Johannsson G, Bengtsson BA, Stavrou S, Kleinberg DL, Cook DM, Phillips LS, Bidlingmaier M, Strasburger CJ, Hackett S, Zib K, Bennett WF \& Davis RJ. Treatment of acromegaly with the growth hormone-receptor antagonist pegvisomant. New England Journal of Medicine 200020 $1210-1211$.

2 Drake WM, Parkinson C, Besser GM \& Trainer PJ. Clinical use of a growth hormone receptor antagonist in the treatment of acromegaly. Trends in Endocrinology and Metabolism 200112 408-413.

3 Stewart PM. Pegvisomant: an advance in clinical efficacy in acromegaly. European Journal of Endocrinology 2003148 (Suppl 2) S27-S32.

4 Veldhuis JD, Bidlingmaier M, Anderson SM, Evans WS, Wu Z \& Strasburger CJ. Impact of experimental blockade of peripheral growth hormone $(\mathrm{GH})$ receptors on the kinetics of endogenous and exogenous $\mathrm{GH}$ removal in healthy women and men. Journal of Clinical Endocrinology and Metabolism $2002 \mathbf{8 7}$ 5737-5745.

5 Thorner MO, Strasburger CJ, Wu Z, Straume M, Bidlingmaier M, Pezzoli SS, Zib K, Scarlett JC \& Bennett WF. Growth hormone (GH) receptor blockade with a PEG-modified GH (B2036-PEG) lowers serum insulin-like growth factor-I but does not acutely stimulate serum GH. Journal of Clinical Endocrinology and Metabolism 1999 $842098-2103$.

6 van der Lely AJ, Hutson RK, Trainer PJ, Besser GM, Barkan AL, Katznelson L, Klibanski A, Herman-Bonert V, Melmed S, Vance ML, Freda PU, Stewart PM, Friend KE, Clemmons DR, Johannsson G, Stavrou S, Cook DM, Phillips LS, Strasburger CJ, Hackett S, Zib KA, Davis RJ, Scarlett JA \& Thorner MO. Long-term treatment of acromegaly with pegvisomant, a growth hormone receptor antagonist. Lancet 2001358 1754-1759.

7 Morrell DJ, Dadi H, More J, Taylor AM, Dabestani A, Buchanan CR, Holder AT \& Preece MA. A monoclonal antibody to human insulin-like growth factor-I: characterization, use in radioimmunoassay and effect on the biological activities of the growth factor. Journal of Molecular Endocrinology 19892 201-206.

8 Drake WM, Rowles SV, Roberts ME, Fode FK, Besser GM, Monson JP \& Trainer PJ. Insulin sensitivity and glucose tolerance improve in patients with acromegaly converted from depot octreotide to pegvisomant. European Journal of Endocrinology 2003149 $521-527$. 
9 Drake WM, Parkinson C \& Akker SA. Successful treatment of resistant acromegaly with a growth hormone receptor antagonist. European Journal of Endocrinology 2001145 451-456.

10 Drake WM, Coyte D, Camacho-Hubner C, Jivanji NM, Kaltsas G, Wood DF, Trainer PJ, Grossman AB, Besser GM \& Monson JP. Optimizing growth hormone replacement therapy by dose titration in hypopituitary adults. Journal of Clinical Endocrinology and Metabolism 199883 3913-3919.
11 Melmed S. Confusion in clinical laboratory GH and IGF-I reports. Pituitary 19992 171-172.

Received 27 August 2004

Accepted 5 October 2004 